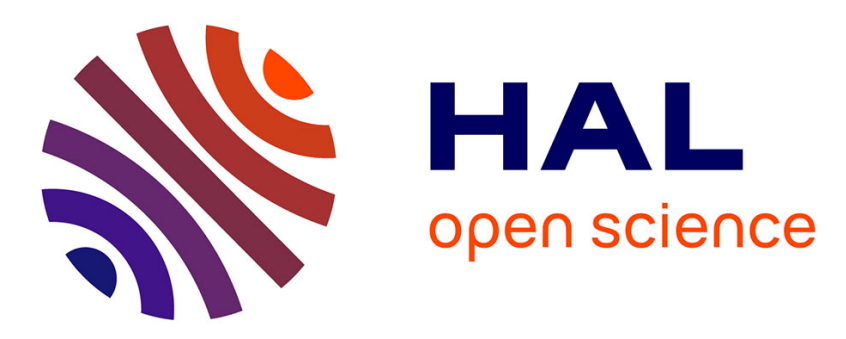

\title{
Nuclear orientation experiments on cerium intermetallic compounds
}

\author{
Angélique Benoit, J. Flouquet, M. Ribault
}

\section{To cite this version:}

Angélique Benoit, J. Flouquet, M. Ribault. Nuclear orientation experiments on cerium intermetallic compounds. Journal de Physique Lettres, 1978, 39 (5), pp.63-66. 10.1051/jphyslet:0197800390506300 . jpa-00231444

\section{HAL Id: jpa-00231444 https://hal.science/jpa-00231444}

Submitted on 1 Jan 1978

HAL is a multi-disciplinary open access archive for the deposit and dissemination of scientific research documents, whether they are published or not. The documents may come from teaching and research institutions in France or abroad, or from public or private research centers.
L'archive ouverte pluridisciplinaire $\mathbf{H A L}$, est destinée au dépôt et à la diffusion de documents scientifiques de niveau recherche, publiés ou non, émanant des établissements d'enseignement et de recherche français ou étrangers, des laboratoires publics ou privés. 


\title{
NUCLEAR ORIENTATION EXPERIMENTS ON CERIUM INTERMETALLIC COMPOUNDS
}

\author{
A. BENOIT, J. FLOUQUET, M. RIBAULT
}

Université Paris-XI, Laboratoire de Physique des Solides (*), 91405 Orsay, France

(Reçu le 6 décembre 1977, révisé le 5 janvier 1978, accepté le 16 janvier 1978)

Résumé. - Des expériences d'Orientation Nucléaire effectuées sur les composés $\mathrm{In}_{3} \mathrm{Ce}, \mathrm{Pb}_{3} \mathrm{Ce}$, $\mathrm{Sn}_{3} \mathrm{Ce}$ montrent que le premier composé est bien ordonné, que $\mathrm{Sn}_{3} \mathrm{Ce}$ est un réseau Kondo et que d'autres expériences doivent être faites pour confirmer l'état Kondo de $\mathrm{Pb}_{3} \mathrm{Ce}$. Une interprétation simple est donnée au comportement de ces terres rares anormales.

\begin{abstract}
Nuclear orientation experiments on $\mathrm{In}_{3} \mathrm{Ce}, \mathrm{Pb}_{3} \mathrm{Ce}, \mathrm{Sn}_{3} \mathrm{Ce}$ show that the first compound is well ordered, that $\mathrm{Sn}_{3} \mathrm{Ce}$ is a Kondo lattice and that further experiments must be performed in order to confirm the Kondo state of $\mathrm{Pb}_{3} \mathrm{Ce}$. A simple interpretation is proposed to explain the behaviour of these abnormal compounds.
\end{abstract}

1. Introduction. - Recent nuclear orientation experiments (N.O.) [1] have shown that the compound $\mathrm{Al}_{2} \mathrm{Ce}$ is well ordered down to $5 \mathrm{mK}$ and that $\mathrm{Al}_{3} \mathrm{Ce}$ appears as a Kondo lattice [2] [3]. From magnetic measurements, this last conclusion is dubious as the crystalline anisotropy of the $| \pm 3 / 2\rangle$ cerium ground state of the crystal field [4] is expected to lead to a strong moment induced by the applied field $H$; in addition a possible long range order as in $\mathrm{Al}_{2} \mathrm{Ce}$ would not be detected by an antiferromagnetic behaviour as this contribution cancels generally in a hexagonal polycrystalline sample. If there is no doubt that the magnetic fluctuations of $\mathrm{Ce}$ moments is higher in $\mathrm{Al}_{3} \mathrm{Ce}$ than in $\mathrm{Al}_{2} \mathrm{Ce}$, it is not well established that $\mathrm{Al}_{3} \mathrm{Ce}$ represents the ideal case of a Kondo lattice described in references [3-5].

Thus we have performed N.O. experiments in other $\mathrm{Ce}$ intermetallic compounds in order to determine at very low temperatures their magnetic ground state as a function of their electronic parameters. All the chosen compounds have a high linear coefficient $\gamma$ of their specific heats, $C=\gamma T$.

2. Experimental conditions. - The radiation nuclei of ${ }^{137 \mathrm{~m}} \mathrm{Ce}$ are obtained by bombarding a lanthanum foil in a $35 \mathrm{MeV}$ proton beam. The samples are prepared by melting a small amount of radioactive $\mathrm{LaCe}$ alloys with the constituents of the intermetallic compound; the lanthanum concentration is lower than 0.5 percent.

(*) Laboratoire associé au C.N.R.S.
The samples are cooled using a dilution refrigerator and the temperature measured by a N.O. thermometer of $\mathrm{Co}^{60} \mathrm{Co}$ reaches $8 \mathrm{mK}$ with an applied field up to $70 \mathrm{kOe}$. The gamma rays emitted along $H$ were detected by a planar $\mathrm{Ge}(\mathrm{Li})$ detector.

3. Representation of the results. - The experimental results are described in terms of the axial anisotropy $E(0)$ which is the difference of warm and cold counts normalized by the warm counts. For a magnetic coupling, if the local quantization axis of every nucleus coincides with $H, E(0)$ must be positive for the ${ }^{137 \mathrm{~m}} \mathrm{Ce}$ nuclei. In the paramagnetic regime [6], the variation of the associated effective field, $H_{\text {eff }}$, with $H$ gives directly the strength of the Kondo coupling assuming : i) the proportionality between $H_{\text {eff }}$ and $M$ the magnetization, ii) a susceptibility law expressed by :

$$
\chi=\frac{\mu_{\mathrm{eff}}^{2}}{3 k_{\mathrm{B}} T_{\mathrm{K}}} .
$$

The hypothesis of a unique axis of quantization is ruled out when interactions occur. For example, in low field for an antiferromagnetic coupling between the spins, the local moments choose to be antiparallel to each other and perpendicular to the applied field ; for such a configuration, the sign of the anisotropy is reversed since the equatorial and axial anisotropies have opposite signs.

4. Results. - In low fields, the long range order of $\mathrm{Al}_{2} \mathrm{Ce}$ has recently been detected by the occurrence 
of a reversed sign of the gamma anisotropy after a full magnetization process [1]. The figure 1 represents the anisotropy $E(0)$, detected under the same conditions for the different compounds at $10 \mathrm{mK}$. $\mathrm{In}_{3} \mathrm{Ce}$ like $\mathrm{Al}_{2} \mathrm{Ce}$ is well ordered with a predominant antiferromagnetic component. It must be underlined that for $\mathrm{In}_{3} \mathrm{Ce}$ contrary to $\mathrm{Al}_{2} \mathrm{Ce}$, the antiferromagnetic component is detected directly in the first magnetization curve.

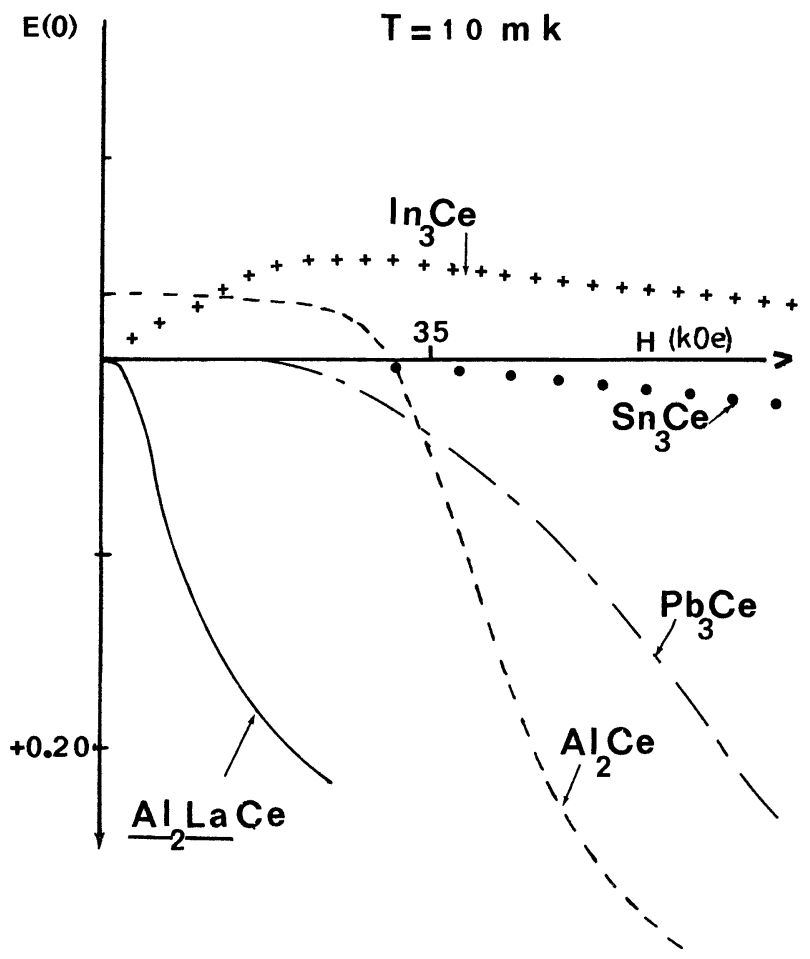

Fig. 1. - For different intermetallic compounds, axial gamma ray anisotropy of ${ }^{137 \mathrm{~m}} \mathrm{Ce}$ nuclei at $10 \mathrm{mK}$ as a function of the applied field.

The $\mathrm{Sn}_{3} \mathrm{Ce}$ sample shows a magnetic response characteristic of an induced moment created by the applied field. From the initial slope of $\partial H_{\text {eff }} / \partial H$, a Kondo temperature can be derived :

$$
T_{\mathrm{K}}=40 \pm 20 \mathrm{~K}
$$

The $\mathrm{Pb}_{3} \mathrm{Ce}$ compound seems to follow a N.O. response very similar to that of the dilute alloy of $\mathrm{Al}_{2} \mathrm{LaCe}$ where the cerium is a Kondo impurity with $\overline{\mathrm{a} T} T_{\mathrm{K}}$ equal to $400 \mathrm{mK}$ [7]. No detectable antiferromagnetic component is observed. A possible Kondo temperature will be :

$$
T_{\mathrm{K}}=3 \pm 1 \mathrm{~K}
$$

5. Discussion. - The $\mathrm{In}_{3} \mathrm{Ce}$ compound has a higher antiferromagnetic component than $\mathrm{Al}_{2} \mathrm{Ce}$ which is, furthermore, not reversed for the strongest applied field $H=70 \mathrm{kOe}$. These two properties are in excellent agreement with the values of the temperature maximum $T_{M}$ of the specific heat reported in table I and also with the highest ordering temperature $T_{\mathrm{N}}$ attributed to $\mathrm{In}_{3} \mathrm{Ce}$. The observation of the antiferromagnetic behaviour of $\mathrm{In}_{3} \mathrm{Ce}$ during the first magnetization process indicates the weakness of its magnetic anisotropy compared to that of $\mathrm{Al}_{2} \mathrm{Ce}$.

\section{TABLE I}

Specific heat results of the $\gamma$ coefficient of the linear temperature dependence and of the observation of a sharp maximum at a temperature $T_{\mathrm{M}}$.

$\begin{array}{lccc} & \gamma \text { in } \mathrm{mJ} / \text { mole }^{2} & T_{\mathbf{M}} \text { in } \mathrm{K} & \text { Ref. } \\ \mathrm{Al}_{2} \mathrm{Ce} & - & - & - \\ \mathrm{In}_{3} \mathrm{Ce} & 180 & 3.8 & {[14]} \\ \mathrm{Pb}_{3} \mathrm{Ce} & 140 & 10.8 & {[20]} \\ \mathrm{Sn}_{3} \mathrm{Ce} & 225 & <1 \mathrm{~K} & {[19]} \\ & 53 & - & {[19]}\end{array}$

A general discussion and a specific comparison of these abnormal rare earth compounds are difficult as many aspects must be considered in order to discuss their particular behaviour. The three main parameters are : i) the local resonant exchange coupling $k-f$ between the localized moment $S$ and the spin of the conduction electrons $s$

$$
H=-2 \Gamma \mathbf{S} . \mathbf{s}
$$

ii) the electronic response of the Fermi sea to this local perturbation which produces an indirect coupling among the localized spin by the wellknown RudermanKittel oscillation related to the Fermi surface; iii) the crystal field which has a strong effect on the Kondo coupling [8] and which may lead to a crystalline anisotropy by the mixing between the different levels with the applied field [9].

Benoit et al. [10] have recently derived a crude model where the Kondo effect is introduced simply by a magnetization law of the single cerium ion (see ref. [6])

$$
M \sim \operatorname{Arctg} g \mu_{\mathrm{B}} H / k_{\mathrm{B}} T_{\mathrm{K}}
$$

and where exchange couplings between the localized moments are restricted to a ferromagnetic interaction and an antiferromagnetic interaction between the first and second neighbours of a linear chain of $\mathrm{Ce}$ ions (the two corresponding exchange constants $J_{1}, J_{2}$ are simply related to $\Gamma^{2}$ ). For classical moments and constant exchange couplings, the ground state at $0 \mathrm{~K}$ is respectively a helical ordered structure, a modulated ordered structure and finally a paramagnetic Kondo Lattice state when the Kondo temperature increases continuously. It must be emphasized that even in the helical magnetic order the local moment of each ion can be strongly reduced from its saturation value.

The neutron and N.O. results on $\mathrm{Al}_{2} \mathrm{Ce}$ which indicate a modulated long range order can be easily understood and the competition between the Kondo and exchange couplings clearly demonstrated. 
The crude model of Benoit $e t$ al. [10] can be applied to any singlet state given either by the Kondo state or the crystal field splitting. The specific characteristic of the Kondo state is the strong resonance of the conduction electrons below $T_{\mathrm{K}}$. In dilute alloys, the occurrence of a strong local density of states at the Fermi level below $T_{\mathrm{K}}$ [12] produces a linear temperature contribution to the specific heat, $C=\gamma T$, which is inversely proportional to the Kondo temperature.

If the magnetic interaction among ions can be reduced to a molecular field associated with the ordering temperature $T_{\mathrm{N}}$, the different values of $\gamma$ can be regarded as the combination of two opposite processes. Firstly, the simple ion property leads to the $\gamma$ enhancement by the Kondo coupling below $T \ll T_{\mathrm{K}}$; secondly the magnetic interactions reduce this enhancement by the decoupling of the Kondo state with the applied field $H=H_{\mathrm{M}}$ (see Schotte and Schotte [13] for the depression of the Kondo anomaly by the applied field).

By analogy with the Blandin-Friedel description of the appearance of local magnetism [21], it can be expected that a maximum of $\gamma$ would be located near the occurrence of long range order. If a $\gamma$ maximum corresponds to the range of $T_{\mathrm{K}}$ of the magnetic modulated structure, the estimation of the Kondocoupling by the $\gamma$ values may lead to spurious results. For example by increasing the pressure (or the ratio $T_{\mathrm{K}} / T_{\mathrm{N}}$ ) the bare Kondo temperature increases but $\gamma$ may increase or decrease depending upon its relative position compared to the $\gamma$ maximum (Fig. 2).

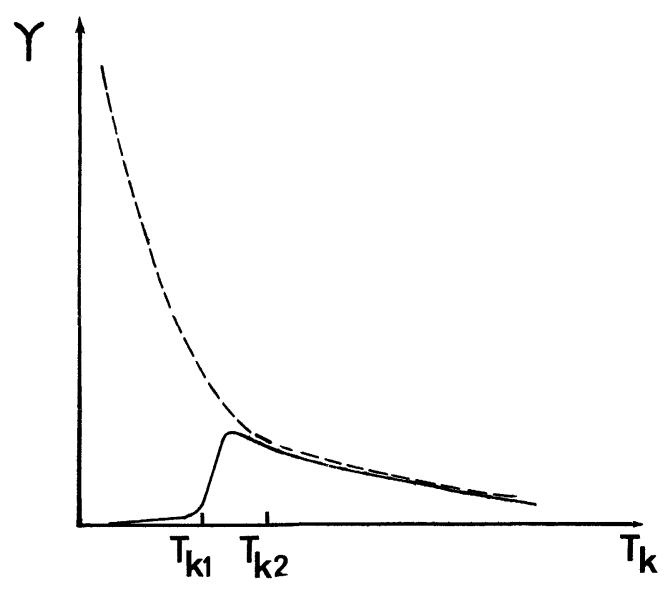

FIG. 2. - Full line, for constant exchange coupling, $J_{1}, J_{2}$, possible variation of $\gamma$ as a function of $T_{\mathrm{K}} / J_{1}$ for the abnormal cerium compounds. For $T_{\mathrm{K}}<T_{\mathrm{K}_{1}}$, a helical structure occurs, $T_{\mathrm{K}_{1}}<T_{\mathrm{K}}<T_{\mathrm{K}_{2}}$ a modulated structure and $T_{\mathrm{K}}>T_{\mathrm{K}_{2}}$ a paramagnetic Kondo lattice. The single Kondo behaviour is drawn as a dashed line.

Theoretically, the parameter of the single ion $\left(T_{\mathrm{K}}\right)$ can be derived from the high temperature results. In table II, we report the values of $\Gamma \rho, T_{\mathrm{K}}$ and $\Delta$ the splitting between the $\Gamma_{7}$ doublet ground state and the $\Gamma_{8}$ quadruplet of the crystal field which are obtained by Lethuillier [14] from its susceptibility
TABLE II

Single ion parameters estimated by Lethuillier from their high temperature susceptibility results [14]

$\begin{array}{lccc} & \Gamma \rho & T_{\mathrm{K}} \text { in } \mathrm{K} & \Delta \text { in K } \\ & - & - & - \\ \mathrm{Al}_{2} \mathrm{Ce} & -0.11 & 0.19 & 150 \\ \mathrm{In}_{3} \mathrm{Ce} & -0.14 & 1.7 & 150 \\ \mathrm{~Pb}_{3} \mathrm{Ce} & -0.07 & 0.007 & 100 \\ \mathrm{Sn}_{3} \mathrm{Ce} & -0.33 & 140 & 45\end{array}$

results ( $\rho$ is the density of states of the conduction electrons at the Fermi level). The weakness of $T_{\mathbf{K}}$ for $\mathrm{Al}_{2} \mathrm{Ce}$ and $\mathrm{Pb}_{3} \mathrm{Ce}$ are dubious.

For $\mathrm{Al}_{2} \mathrm{Ce}$, the low value of $T_{\mathrm{K}}$ seems to be ruled out by both N.O. and neutron measurements which are understood only if $T_{\mathrm{K}} \sim T_{\mathrm{N}}$. It must be emphasized that Lethuillier's determination is derived from the study of dilute alloys of $\mathrm{Al}_{2} \mathrm{LaCe}$ but that, by measur-

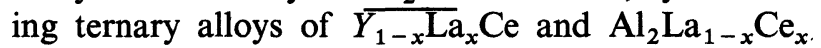
Steglich [15] has recently given an evaluation of $T_{\mathrm{K}} \sim 6 \mathrm{~K}$ in better agreement with our conclusions. Likewise for $\mathrm{Pb}_{3} \mathrm{Ce}$, the weakness of $T_{\mathrm{K}}$ and $T_{\mathrm{N}}$ given in tables I-II cannot explain the low saturation of the magnetization observed in our N.O. experiments.

This controversy seems to illustrate the difficulty in deriving quantitatively the bare parameter of the single ion from a high temperature susceptibility measurement. In fact for these abnormal rare earths another interpretation of this apparent discrepancy is that the single ion parameter of Benoit et al. [10] is linked more to the collective Kondo condensation described by Jullien et al. [3] than to the bare parameter of every ion. This appears clearly as their low temperature properties cannot be understood in a simple scheme of individual $4 \mathrm{f}$ virtual levels [14].

The $\mathrm{Sn}_{3} \mathrm{Ce}$ compound is characterized by a Kondo coupling which is rather weak for an interpretation of its behaviour in terms of an intermediate valency. At low temperature our estimation of $T_{\mathrm{K}}=40 \mathrm{~K}$ is lower than the value $T_{\mathrm{K}} \sim 140 \mathrm{~K}$ obtained from the high temperature susceptibility results [15]; this difference is in excellent agreement with a well resolved crystal field splitting of $\Delta \sim 50 \mathrm{~K}$. The $\mathrm{Sn}_{3} \mathrm{Ce}$ compound can certainly be described as a Kondo lattice with an ionic description of the Ce moment. This remark is supported by the small variation of the lattice parameter with the temperature [17] and the absence of any variation of the isomeric shift of $\mathrm{Sn}$ in $\mathrm{Sn}_{3} \mathrm{Ce}$ below the characteristic temperature $\theta \sim 140 \mathrm{~K}$ [18].

6. Conclusion. - Our N.O. experiment shows that $\mathrm{In}_{3} \mathrm{Ce}$ is well ordered like $\mathrm{Al}_{2} \mathrm{Ce}$. The weakness of the crystalline anisotropy of $\operatorname{In}_{3} \mathrm{Ce}$ suggests that this compound can be either in the helical range of $T_{\mathrm{K}}$ or near the long range magnetic instability (point $T_{\mathbf{K}_{2}}$ ). Up to date, the simple example of a Kondo lattice 
seems to be $\mathrm{Sn}_{3} \mathrm{Ce}$ which is near a valency instability. Our experiments suggest that the $\mathrm{Pb}_{3} \mathrm{Ce}$ compound is another excellent case, other experiments must be performed in order to test this conclusion.

All the abnormal compounds measured here by N.O. seem to be qualitatively well understood in terms of a competition between the Kondo lattice condensation and the long range order due to magnetic interactions between neighbours. The exact description of the $\mathrm{Al}_{3}$ Ce compound is still unclear; the crossing point $T_{\mathbf{K}_{1}}$ may have important topological proprieties.

The authors wish to thank Dr. B. Coqblin, Dr. B. Cornut, Dr. G. Chouteau, Dr. R. Jullien, Dr. P. Lethuillier and Dr. R. Tournier for stimulating discussions. We have especially benefited from the hospitality of the cyclotron laboratory of Orléans.

\section{References}

[1] Benoit, A., Flouguet, J., Ribault, M., Chapellier, M., to be published (1977) Solid State Commun.

[2] MotT, N. F., Phil.Mag. 30 (1974) 403.

[3] Doniach, S., Proc. Conf. On Valence fluctuations, Rochester 76-Ed. Parks (Plenum Press) 169.

Jullien, R., Fields, J., DoniaCh, S., Phys. Rev. Lett. 38 (1977) 1500.

[4] Murani, A. P., KNorr, K., Buschow, K. H. J., Second Conference on Crystal field effects in metals, Zurich (1976).

Edelstein, A. S., Majewski, R. E. and Blewitt, T. H., Conference Rochester (1976) 115.

[5] TOurnier, R. and HoltZberg, F., Conference Rochester (1976) 312.

[6] FlouQuet, J., Prog. Low Temp. Phys. Vol. VII (to be published North Holland).

[7] Benort, A., Flouguet, J., SAnchez, J., Solid State Commun. $13(1973) 1581$.

[8] Cornut, B., CoQblin, B., Phys. Rev. B 5(1972) 4541.

[9] See for $\mathrm{Al}_{2} \mathrm{Ce}$ : Barbara, B., Rossignol, M. F., Purwins, H. G. and WALKER, E., Solid State Commun. 17 (1975) 1525.
[10] Benoit, A., Flouguet, J., Ribault, M., to be published.

[11] Barbara, B., Boucherle, J. X., Buevoz, J. L., RossiGNol, M. F. and Schweizer, J., Solid State Commun. 24 (1977) 481.

[12] Yamada, K., Prog. Theor. Phys. 53 (1975) 970.

[13] Schotтe, K. D. and Schotтe, U., Phys. Lett. 55 A (1975) 38.

[14] Le Thuillier, P., Thesis Grenoble (1976).

[15] Steglich, F., Advances in Solid State Physics XVII (1977) 319.

[16] Tsuchida, T. and Wallace, W. E., J. Chem. Phys. 43 (1965) 3811.

[17] Harris, R. and Raynor, G. V., J. Less Common. Met. 9 (1965) 7.

[18] Shenoy, G. K., Dunlop, B. D., Kalvius, G. M., Toxen, A. M. and Gambino, R. J., J. Appl. Phys. 41 (1970) 1317.

[19] Cooper, J. R., Rizutto, C. and Olcese, G., J. Physique Colloq. 32 (1971) C1-1136.

[20] Van Diepen, A. M., Craig, R. S. and Wallace, W. E., J. Phys. Chem. Solids 32 (1971) 1867.

[21] Blandin, A., Friedel, J., J. Physique 20 (1959) 160. 